\title{
In Vitro Evaluation of Molecular Tumor Targets in Nuclear Medicine: Immunohistochemistry Is One Option, but Under Which Conditions?
}

\author{
Jean Claude Reubi \\ Institute of Pathology, University of Berne, Berne, Switzerland
}

\begin{abstract}
The identification of new molecular targets for diagnostic and therapeutic applications using in vitro methods is an important challenge in nuclear medicine. One such method is immunohistochemistry, increasingly popular because it is easy to perform. This review presents the case for conducting receptor immunohistochemistry to evaluate potential molecular targets in human tumor tissue sections. The focus is on the immunohistochemistry of G-protein-coupled receptors, one of the largest families of cell surface proteins, representing a major class of drug targets and thus playing an important role in nuclear medicine. This review identifies common pitfalls and challenges and provides guidelines on performing such immunohistochemical studies. An appropriate validation of the target is a prerequisite for developing robust and informative new molecular probes.
\end{abstract}

Key Words: immunoassay; molecular imaging; general oncology; GPCR; immunohistochemistry; novel molecular tumor targets

J Nucl Med 2017; 58:1885-1887

DOI: 10.2967/jnumed.117.197582

$\mathbf{T}$ he discovery of novel molecular tumor targets is of key importance in nuclear medicine. For successful tumor imaging and targeted tumor radiotherapy in patients, nuclear medicine needs to rely on adequate identification of specific tumor targets with in vitro methods in large series of human tumor samples. One such specific tumor target is a receptor to which only the natural ligand or specifically designed molecules will be able to bind with high affinity. In addition, to be a specific tumor target, a receptor preferably must be sufficiently expressed only in tumor cells, not in other tissues, organs, or compartments. In the literature, there are numerous such examples of receptors massively overexpressed in tumors but not in normal physiologic tissues. Clearly, nuclear medicine is dependent on target specificity if it wants to fulfill its role of accurately diagnosing tumors and safely treating tumors with as few side effects as possible.

The G-protein-coupled receptors (GPCRs), one of the largest families of cell surface proteins, represent one such ideal target for nuclear medicine. Not only do they regulate, after activation by

Received Jun. 14, 2017; revision accepted Aug. 10, 2017.

For correspondence or reprints contact: Jean Claude Reubi, Institute of Pathology, University of Berne, Murtenstrasse 31, $\mathrm{CH}-3008$ Berne, Switzerland.

E-mail: reubi@pathology.unibe.ch

Published online Sep. 14, 2017.

COPYRIGHT (C 2017 by the Society of Nuclear Medicine and Molecular Imaging. hormones and neurotransmitters, a considerable part of the physiologic processes in the body, but they also represent a major class of drug targets and thus play an increasingly important role in medicine. Indeed, more than $30 \%$ of the clinically marketed drugs do act through GPCRs and are therapeutically successful in a large spectrum of human diseases. It is therefore evident that reliable information on the expression and precise distribution of GPCRs, particularly in normal and diseased human tissues, is highly desirable. The cellular density of GPCRs is usually considerably lower than that of other cellular parameters-such as hormones, for instance-sometimes challenging their detection with current in vitro methods. The present article focuses on GPCRs, even though other classes of targets (enzymes, kinases, transporters, steroid hormones, and growth factor receptors) would also have been subjects of interest.

\section{VALIDATION}

It is of prime importance that GPCRs be evaluated in vitro first, in a large series of human tumor samples, so that clear information on their incidence and density can be given for these tissues. GPCRs can be detected in vitro in human tissues by various methods. Human tissue samples are not homogeneous but extremely complex, as they usually include many distinct cell types and compartments (epithelial cells, endocrine cells, nerves, vessels, and immune cells, among others) as well as pathologic tissues (e.g., tumors, inflammatory tissues, and degenerative tissues). Therefore, it is mandatory to use morphologic methods to accurately identify the cell types that do express GPCRs. Various morphologic methods exist to measure and localize these receptors, including receptor messenger RNA detection with in situ hybridization; receptor protein localization with in vitro radioligand binding using receptor autoradiography, a method based on the same principle as in vivo imaging in patients, namely the binding to tumor tissue of a radiolabeled analog showing specificity and high affinity to the investigated receptor; and immunohistochemistry with specific antibodies, the subject of the present commentary.

Immunohistochemistry has become popular because it is an easy-to-perform morphologic method. It has an excellent resolution at the cellular level; it can be performed on readily available formalin-fixed tissues rather than on the more difficult-to-obtain fresh-frozen material; it has a rapidly increasing number of available commercial and noncommercial antibodies; and its data are generally considered easy to interpret (see below for caveats, however). The consequence is a plethora of papers describing immunohistochemistry findings for GPCRs in human tissues. 
Unfortunately, several of the published papers show that data are often questionable because of the use of poorly validated antibodies or protocols $(1,2)$. Several papers have therefore recently documented the need for relevant, well-designed immunohistochemical protocols and correctly characterized antibodies (3-6). The authors of these papers also suggest that, to prevent poorly relevant publications on GPCR immunohistochemistry and subsequent further controversial discussions, the scientists publishing immunohistochemistry studies should follow recommendations or even clear rules $(3,4,7)$. An initiative to introduce such recommendations has recently been taken by the journal Endocrinology (8); adherence to such a strategy by all journals reporting immunohistochemical data would be beneficial. Valuable in this regard is also a set of recommendations on the validation of immunohistochemical assays in diagnostic settings, recently published by the College of American Pathologists (9). Because nuclear medicine is basically dependent on the precise definition and identification of receptor targets in vitro, basic scientists in the nuclear medicine field should be aware of this initiative.

\section{IMMUNOHISTOCHEMISTRY REQUIREMENTS}

What is necessary to make an immunohistochemistry investigation convincing? At first, rather basic information is needed, namely a full description of the antibody characteristics (antibody name, manufacturer, code number, antigen sequence if known, species raised in, monoclonal/polyclonal designation, clone designation if applicable, lot number for polyclonal antibodies). It should further be confirmed that the antibody has been tested successfully in cell lines expressing the receptor, and negative controls in cell lines devoid of the receptor or in wild-type/knockout mice should also be provided $(3,4,10,11)$. Preferably, such data should be available for both fresh frozen and the corresponding formalin-fixed materials.

\section{TESTING IN HUMAN TISSUES}

Validation of a GPCR antibody in cell lines does not necessarily warrant its specificity in human tissues. The antibody needs to be further tested in human tissues.

\section{Control Tissues}

One should take care to identify and use adequate control tissues-as far as they are known-to validate the chosen antibody; that is, choose positive controls containing a known,

\section{NOTEWORTHY}

- To prevent poorly relevant publications on GPCR immunohistochemistry, scientists publishing immunohistochemistry studies should follow recommendations or even clear rules.

- Validation of a GPCR antibody in cell lines does not necessarily warrant its specificity in human tissues.

- For GPCRs, it is not sufficient to simply show the presence of the immunoreactive product in the cell; it is essential to document where in the cell the immunohistochemical reaction product is localized.

- Accurate in vitro target definition is crucial for clinical nuclear medicine, because it reduces the number of unnecessary clinical trials on poorly defined targets.

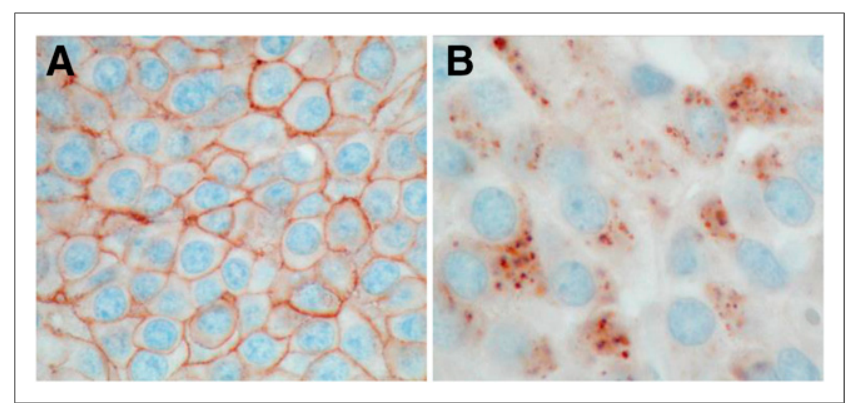

FIGURE 1. (A) Immunohistochemistry of $s t_{2}$ in neuroendocrine tumor taken from octreotide-naïve patient. Strong membrane-bound somatostatin $\mathrm{sst}_{2}$ receptor staining is seen in tumor cells. (B) Immunohistochemistry of somatostatin sst $_{2}$ receptor in neuroendocrine tumor from patient who received intravenous infusion of octreotide during resection of tumor. Because of octreotide application, receptors are not membrane-bound but have been internalized after octreotide binding and show typical endosome-related intracellular pattern.

established human target tissue expressing the receptor of interest. Adjacent nontarget tissue should clearly not react, that is, should "stain negatively." Antigen preabsorption tests, or negative controls, performed with an excess of antigenic peptide (if available) on adjacent sections of the same tissue samples should also be provided. Various antigen retrieval methods and different antibody concentrations should be applied in initial testing. Also, frozen tissues may be tested. In many instances, immunohistochemistry works on frozen tissues; this is important because some targets do not survive formalin fixation and need to be analyzed on frozen tissues. All results should be carefully evaluated to obtain an optimal protocol. Once the protocol is established, any further tests should strictly adhere to it. Precaution should be taken when pancreatic islets are used as positive controls for validation of hormone receptors - as commercial providers often do-because the islets have been shown to be occasionally "immunostained" nonspecifically (12).

\section{Localization Within Cells}

For GPCRs, it is not sufficient to simply show the presence of the immunoreactive product in the cell; it is essential to document where in the cell the immunohistochemical reaction product is localized. By definition, GPCRs are cell surface receptors with 7 transmembrane-spanning domains. Therefore, under normal conditions, we expect to see immunoreactivity localized at the cell membrane $(10,11,13-15)$. A typical example of the somatostatin receptor $\mathrm{sst}_{2}$ expressed in a neuroendocrine tumor is shown in Figure 1A. This membrane-bound localization of such a GPCR is at odds with the cellular location for other receptor families, such as the androgen receptors (16), located by definition in the cytoplasm or nucleus. For GPCRs, diffuse cytoplasmic immunohistochemical staining is a doubtful result and most likely nonspecific but is often erroneously interpreted as specific staining demonstrating internalized receptors. Surely, GPCRs can be actively internalized from the cell membrane into the cell. Internalization is even part of the physiologic mechanism of action for many GPCRs. A condition usually necessary for this phenomenon to occur is an acute receptor stimulation by agonist treatment that triggers internalization of the receptor-ligand complex. Internalized receptors have a particular intracellular distribution, as they are usually internalized in 
circumscribed endosomes; thus, they are not diffusely distributed in the cytoplasm $(17,18)$. Figure 1B shows an example of internalized sst $_{2}$ receptors in a neuroendocrine tumor from a patient who received an infusion of the somatostatin analog octreotide during surgical removal of his tumor. As is evident in both examples of Figure 1, an illustration at high magnification is required to precisely evaluate the cellular localization of receptors. Often, authors do not take advantage of the high resolution of immunohistochemistry but limit themselves to publishing overview pictures of low magnification that sometimes mask poor-quality immunostaining.

\section{Western Blot Testing}

One should provide a Western blot with the used antibody in the same human tissues that were found to be immunohistochemically positive. Such a blot should confirm the identity of the receptor detected by immunohistochemistry by showing a single, specific band of the expected molecular weight $(13,15,17)$.

\section{Comparison with Other Receptor-Measuring Methods}

One should compare the immunohistochemistry-based data with data obtained using another morphologic receptor-measuring method (in vitro receptor autoradiography, in situ hybridization) on the same samples. Although of fundamental importance, such a specificity test of course involves considerable additional work $(13,15,19)$ and is therefore often omitted. It is, however, important to confirm the immunohistochemistry results against alternative methods such as receptor binding since the epitope identified by immunohistochemistry does not necessarily correspond to the binding site of the radioligand. In vitro receptor autoradiography is particularly suitable to analyze targets for nuclear medicine, as it is based on the high-affinity binding of a radiolabeled compound to the receptor and therefore represents the in vitro method corresponding to the in vivo imaging.

\section{Comparison with Other Antibodies}

Ideally, one should compare the obtained GPCR immunohistochemical data with the immuno-localization of the same GPCR using another antibody recognizing a different epitope of the receptor, when such a well-validated antibody is available (19).

\section{Optimal Formalin Fixation}

For every immunohistochemistry study, an optimal formalin fixation of the human tissue samples, according to the standard rules of surgical pathology, is mandatory (9).

In consideration of the enormous number of future drug targets and disease biomarkers (20-22), it is particularly relevant to use adequate in vitro methods to define the tumor target. Putting most of the above-mentioned recommendations into practice will likely prevent unnecessary controversies and reduce experimental discrepancies, as recently shown by examples in the field of receptors for somatostatin, chemokines, and glucagonlike peptide $1(3,4,10,11,23,24)$.

\section{CONCLUSION}

Implementation of the tests described in this article would not only considerably add to the quality of published immunohistochemistry papers but also help in reproducing important new data and permitting more straightforward scientific progress. In particular, accurate in vitro target definition is crucial for clinical nuclear medicine, by reducing the number of unnecessary clinical trials on poorly defined targets.

\section{DISCLOSURE}

No potential conflict of interest relevant to this article was reported.

\section{REFERENCES}

1. Gier B, Butler PC, Lai CK, Kirakossian D, DeNicola MM, Yeh MW. Glucagon like peptide-1 receptor expression in the human thyroid gland. J Clin Endocrinol Metab. 2012;97:121-131.

2. Beer M, Montani M, Gerhardt J, et al. Profiling gastrin-releasing peptide receptor in prostate tissues: clinical implications and molecular correlates. Prostate. 2012;72:318-325.

3. Drucker DJ. Incretin action in the pancreas: potential promise, possible perils, and pathological pitfalls. Diabetes. 2013;62:3316-3323.

4. Pyke C, Knudsen LB. The glucagon-like peptide-1 receptor-or not? Endocrinology. 2013;154:4-8

5. Saper CB. A guide to the perplexed on the specificity of antibodies. $J$ Histochem Cytochem. 2009;57:1-5.

6. Michel MC, Wieland T, Tsujimoto G. How reliable are g-protein-coupled receptor antibodies? Naunyn Schmiedebergs Arch Pharmacol. 2009;379:385-388.

7. Reubi JC. Strict rules are needed for validation of g-protein-coupled receptor immunohistochemical studies in human tissues. Endocrine. 2014;47:659-661.

8. Gore AC. Editorial: antibody validation requirements for articles published in Endocrinology. Endocrinology. 2013;154:579-580.

9. Fitzgibbons PL, Bradley LA, Fatheree LA, et al. Principles of analytic validation of immunohistochemical assays: guideline from the College of American Pathologists pathology and laboratory quality center. Arch Pathol Lab Med. 2014;138:1432-1443.

10. Fischer T, Nagel F, Jacobs S, Stumm R, Schulz S. Reassessment of cxcr4 chemokine receptor expression in human normal and neoplastic tissues using the novel rabbit monoclonal antibody umb-2. PLoS One. 2008;3:e4069.

11. Fischer T, Doll C, Jacobs S, Kolodziej A, Stumm R, Schulz S. Reassessment of sst2 somatostatin receptor expression in human normal and neoplastic tissues using the novel rabbit monoclonal antibody umb-1. J Clin Endocrinol Metab. 2008;93:4519-4524.

12. Dichmann DS, Rescan C, Frandsen U, Serup P. Unspecific labeling of pancreatic islets by antisera against fibroblast growth factors and their receptors. J Histochem Cytochem. 2003;51:397-400.

13. Waser B, Blank A, Karamitopoulou E, Perren A, Reubi JC. Glucagon-likepeptide-1 receptor expression in normal and diseased human thyroid and pancreas. Mod Pathol. 2015;28:391-402.

14. Reubi JC, Schonbrunn A. Illuminating somatostatin analog action at neuroendocrine tumor receptors. Trends Pharmacol Sci. 2013;34:676-688.

15. Körner M, Waser B, Schonbrunn A, Perren A, Reubi JC. Somatostatin receptors subtype 2a immunohistochemistry using a new monoclonal antibody selects tumors suitable for in vivo somatostatin receptor targeting. Am J Surg Pathol. 2012;36:242-252.

16. Shyr CR, Chen CC, Hsieh TF, et al. The expression and actions of androgen receptor in upper urinary tract urothelial carcinoma (UUTUC) tissues and the primary cultured cells. Endocrine. 2013;43:191-199.

17. Reubi JC, Waser B, Cescato R, Gloor B, Stettler C, Christ E. Internalized sst2 receptors in neuroendocrine tumors of octreotide-treated patients. J Clin Endocrinol Metab. 2010;95:2343-2350.

18. Waser B, Tamma ML, Cescato R, Maecke HR, Reubi JC. Highly efficient in vivo agonist-induced internalization of sst 2 receptors in somatostatin target tissues. J Nucl Med. 2009;50:936-941.

19. Körner M, Eltschinger V, Waser B, Schonbrunn A, Reubi JC. Value of immunohistochemistry for somatostatin receptor subtype sst2a in cancer tissues: lessons from the comparison of anti-sst2a antibodies with somatostatin receptor autoradiography. Am J Surg Pathol. 2005;29:1642-1651.

20. Thul PJ, Akesson L, Wiking M, et al. A subcellular map of the human proteome. Science. 2017;356:eaal3321.

21. Lindskog C. The potential clinical impact of the tissue-based map of the human proteome. Expert Rev Proteomics. 2015;12:213-215.

22. Uhlén M, Fagerberg L, Hallstrom BM, et al. Proteomics: tissue-based map of the human proteome. Science. 2015;347:1260419.

23. Chinezu L, Vasiljevic A, Jouanneau E, et al. Expression of somatostatin receptors, sstr2a and sstr5, in 108 endocrine pituitary tumors using immunohistochemical detection with new specific monoclonal antibodies. Hum Pathol. 2014;45:71-77.

24. Pyke C, Heller RS, Kirk RK, et al. Glp-1 receptor localization in monkey and human tissue; novel distribution revealed with extensively validated monoclonal antibody. Endocrinology. 2014;155:1280-1290. 